\title{
Low Intensity Low Frequency Ultrasound Surface Acoustic Wave Treatment for Metatarsal Fractures
}

\section{Jonathan Rosenblum ${ }^{1 *}$, Sean Rosenblum ${ }^{2}$ and Andy Karpf ${ }^{3}$}

${ }^{1}$ Private Practice, Jerusalem, Israel

2Private Practice, Lodi, NJ, USA

${ }^{3}$ Private Practice, Tel Aviv, Israel

*Corresponding author: Jonathan Rosenblum, 17 Shimon St, Bet Shemesh, Israel 99543, Tel: +972 50595 5161; E-mail: diabfootman@gmail.com Received date: June 30, 2017; Accepted date: August 07, 2017; Published date: August 17, 2017

Copyright: (C) 2017 Rosenblum J, et al. This is an open-access article distributed under the terms of the Creative Commons Attribution License, which permits unrestricted use, distribution and reproduction in any medium, provided the original author and source are credited.

\begin{abstract}
Fractures are among the most common injuries we come across. Following is one such case that presents and optional way of fracture healing at a decreased time to fracture union and increased fracture union rate through the use of ultrasonic waves. Reported here are cases of 6 where healing was continued using low intensity low frequency ultrasound diathermy patch for the treatment of metatarsal fracture.
\end{abstract}

Keywords: Metatarsal; Low intensity ultrasound; Fracture healing

\section{Introduction}

Adjuncts to the treatment of fracture healing are aimed at decreasing time to fracture union and improving fracture union rates. Low-intensity pulsed ultrasound is emerging as a safe, cost-effective and reliable treatment for both fresh fractures and fracture nonunions [1].

The effect of ultrasound on the healing of cortical fractures has been reported in closed or grade-I open tibial fractures. Ultrasound treatment consisting of $30 \mathrm{~mW} / \mathrm{cm}^{2}$ for $20 \mathrm{~min} /$ day led to a significant (24\%) reduction in the time to clinical healing (average, $86 \pm 5.8$ days in the treatment group compared with $114 \pm 10.4$ days in the control group; $\mathrm{p}=0.01$ ). A $38 \%$ decrease in the time to overall (clinical and radiographic) healing (average, $96 \pm 4.9$ days in the treatment group compared with $154 \pm 13.7$ days in the control group; $\mathrm{p}=0.0001$ ). The patients' compliance with daily use of the ultrasound device was high, and there were no complications related to its use [2].

We report use of a novel low intensity low frequency ultrasound diathermy (LILFU) patch for the treatment of metatarsal (MT) fractures in a series of 6 patients where the healing was expedited.

\section{Case Presentation}

Six patients (three men, three women) aged 20-47 years had presented with solitary fractures of a metatarsal (5th MT in five, 3rd MT in one) with prior treatment with plaster cast immobilization for 3 - 12 weeks. All were treated with Surface Acoustic Wave (SAW) LILFU patch (NanoVibronix Inc. Elmsford, NY). Five were treated for three weeks and one was treated for two weeks. Xray evidence of healing was present in all 6 patients at the end of their treatment with SAW. There was a reported average return to normal function of $96 \%$ (Table 1).

\begin{tabular}{|c|c|c|c|c|c|c|c|c|c|c|}
\hline Pt No. & Age(Yrs) & Sex & Fracture Location & $\begin{array}{l}\text { Duration } \\
\text { before } \\
\text { Presentation }\end{array}$ & Cast & $\begin{array}{l}\text { Treated with } \\
\text { SAW (days) }\end{array}$ & $\begin{array}{l}\text { Pain pre } \\
\text { Treatment }\end{array}$ & $\begin{array}{l}\text { Pain Post - } \\
\text { Treatment }\end{array}$ & $\begin{array}{l}\text { Healing } \\
\text { Evidence On } \\
\text { Xray }\end{array}$ & $\begin{array}{l}\text { Return to } \\
\text { function (\%) }\end{array}$ \\
\hline 1 & 20 & M & 5th MT base & 21 days & $\mathrm{Y}$ & 14 & 8 & 3 & $\mathrm{Y}$ & 100 \\
\hline 2 & 26 & $\mathrm{~F}$ & 5th MT base & 8 weeks & Y & 21 & 9 & 1 & $\mathrm{Y}$ & 100 \\
\hline 3 & 46 & M & 5th MT base & 12 weeks & $\mathrm{Y}$ & 21 & 6 & 1 & $\mathrm{Y}$ & 90 \\
\hline 4 & 21 & M & 5th MT shaft & 21 days & Y & 21 & 10 & 2 & Y & 90 \\
\hline 5 & 47 & $\mathrm{~F}$ & $\begin{array}{l}\text { 3MT shaft stress } \\
\text { Fracture }\end{array}$ & 12 weeks & $\mathrm{N}$ & 21 & 8 & 2 & $\mathrm{Y}$ & 100 \\
\hline 6 & 44 & $\mathrm{~F}$ & 5th MT shaft & 21 days & $\mathrm{Y}$ & 21 & 8 & 1 & $\mathrm{Y}$ & 100 \\
\hline
\end{tabular}

Table 1: Clinical observations.

Average pain score (VAS) reduced from pre-treatment average of $9.8 / 10$ to post-treatment average of $2 / 10$.
Patient is a 21 year old male soldier who presented with a transverse fracture of the proximal 5th MT shaft secondary to an inversion injury of the ankle. Patient was treated conservatively for 2 weeks before 
presentation with an elastic bandage. On examination, there was a mildly edematous foot with contusion over the dorsolateral portion of the foot and pain with weight bearing and severe pain on palpation at the point of the fracture line and the styloid process. Treatment with SAW device (Nanovibronix Inc. Elmsford, NY USA) was initiated for 3 two hour sessions daily for two weeks. Pain was relieved by day 2 of the treatment. By the end of the second week the edema was almost resolved and the patient was able to bear weight and ambulate using only a cane. The presenting pain on palpation along the lateral aspect of MT5 was totally resolved by the second week of treatment. Radiologically there was callus seen with bridging across the whole of the fracture line at this time (Figure 1).

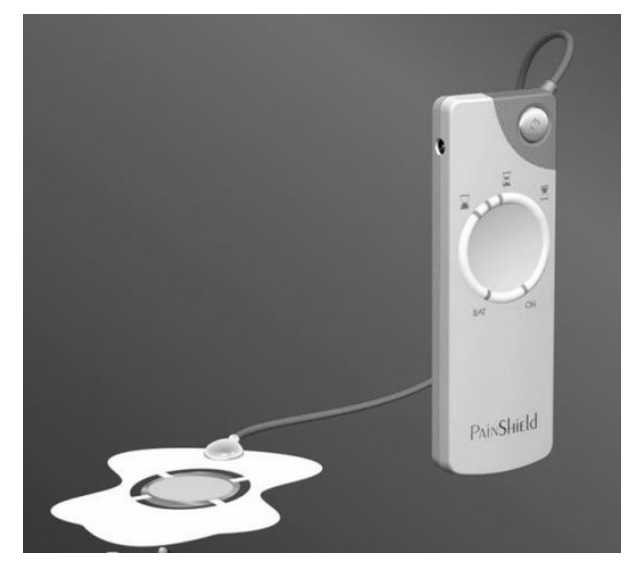

Figure 1: SAW LILFU device (NanoVibronix Inc. Elmsford, NY USA).

\section{Discussion}

Ultrasound stimulates angiogenesis, thus increasing blood flow to the fracture site and inherently delivering key components, such as growth factors and cytokines that are necessary for the normal healing process [3].

Ultrasound stimulates chondrogenesis and cartilage hypertrophy, resulting in an earlier onset of endochondral formation and thus leading to an increase in stiffness and strength of the fracture site [4,5].

Conventional Ultrasound High Frequency 1-3 $\mathrm{MHz}$ had been earlier used in fracture healing as an adjunct. It transmits energy locally and deeply into the body without focusing on superficial structures. This can cause a "Deep Overheat" which clinically presents with cavitation and thermal energy. In clinical practice conventional ultrasound is expensive and the implements are bulky. Because of this, regular use of ultrasound has not been successfully accepted in the traditional orthopedic armamentarium for fracture healing, despite an impressive evidence base. Moreover, it is therapist dependent, time consuming and work intensive for the therapist. Human therapist factor causes overall treatment costs to increase greatly.

\section{Low frequency ultrasound}

Earlier studies have established biological effects of Low frequency Ultrasound including: pain reduction [6-8], ncreased protein and collagen synthesis as well as stimulation of interleukin B8, increased proliferation of fibroblasts and osteoblasts, stimulation of neoangiogenesis, increased production of vascular endothelial growth factor, stimulation of nitric oxide and prostaglandin E2 production $[9,10]$.

\section{Rosenblum's callus}

The presence of a unique callus formation was noted in the patients treated with SAW LILFU, both in these reported cases as well as in other fracture patients,. In contradistinction to the usual domed and rounded callus or the perpendicular bridging across the fracture line, patients treated with SAW developed a peaked spiked callus that resorbed with time. This callus was planarly parallel to the placement of the patch and extended perpendicularly to the patch (Figure 2).

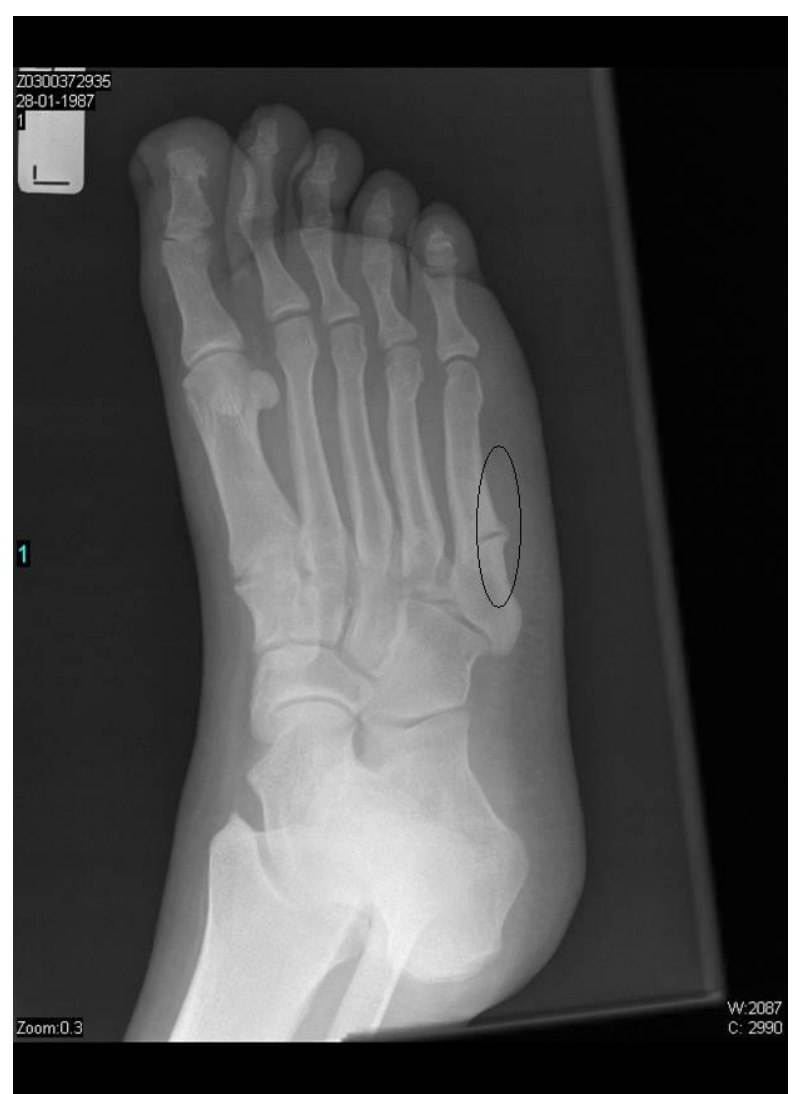

Figure 2: Rosenblum sign- note the one-sided peaked callus.

The ultrasound devices in the orthopedic market today are mostly high energy -high frequency $(\mathrm{MHz})$ devices. The principal reasons for this are the technical barriers to producing a low frequency-low energy device that can be easily applied in an independent manner. The salient problems are: Low frequency devices require transducers that must be about 10 times thicker than that of the $\mathrm{MHz}$ device, a large transducer is difficult to manipulate and its power supply must be 20 times greater than the $\mathrm{MHz}$ device.

Current lower intensity devices are not easily applicable for many hours at a time. The evaluated device is a portable, battery operated, low intensity low frequency ultrasound (LILFU) SAW patch system (Figure 1). It sustains a level of energy kept at a safe, low level while administering therapeutic ultrasound, creating a slow release ultrasound effect on the targeted area of injury. SAW can be used up to 
ten hours continuously or several times a day. The maximum energy output level of this device is lesser than $100 \mathrm{~mW} / \mathrm{cm}^{2}$. Thus the device could be safely used continuously, as per American Institute of Ultrasound in Medicine (AIUM) guidelines showing no adverse bio effects. The novel approach of delivering ultrasound allows for longer periods of treatment time while keeping the total amount of energy exposure of the body well below the noxious level as per the guidelines of AIUM.

The SAW LILFU device is used to generate continuous wave ultrasound at $90 \mathrm{kHz}$ with a power output of $0.4 \mathrm{~W}$, through a reusable/disposable patch with applicator that covers an active area of about $6 \mathrm{~cm}^{2}$. The small applicator allows treatment of less accessible body parts viz., the heel, the achilles tendon and the wrist. The device produces no significant sensation at the treatment site other than slight warming. Using the device overnight ensures a high rate of compliance as it is exceedingly simple to use and does not interfere with the patient's daily routine.

\section{Conclusion}

The LILFU Surface Acoustic Wave (SAW) device was found clinically effective in expediting healing of metatarsal fractures. Further study and a randomized controlled prospective study are required to further qualify the effect.

\section{References}

1. Siska PA, Gruen GS, Pape HC (2008) External adjuncts to enhance fracture healing: what is the role of ultrasound? Injury 39: 1095-1105.
2. Heckman JD, Ryan JP, Frey JJ, Kilcoyne RF, McCabe J, et al. (1994) Acceleration of tibial fracture-healing by non-invasive low-intensity pulsed ultrasound. J Bone Joint Surg Am 76: 26-34.

3. Rawool D, Goldberg B, Forsberg F, Winder A, Talish R, et al. (1998) Power Doppler assessment of vascular changes during fracture treatment with low intensity ultrasound. Trans Radiol Soc North Am 83: 1185.

4. Wang SJ, Lewallen DG, Bolander ME, Chao EY, Ilstrup DM, et al. (1994) Low intensity ultrasound treatment increases strength in a rat femoral fracture model. J Orthop Res 12: 40-47.

5. Yang KH, Parvizi J, Wang SJ, Lewallen DG, Kinnick RR, et al. (1996) Exposure to low-intensity ultrasound increases aggrecan gene expression in a rat femur fracture model. J Orthop Res 14: 802-809.

6. Klaiman MD, Shrader JA, Danoff JV, Hicks JE, Pesce WJ, et al. (1998) Phonophoresis versus ultrasound in the treatment of common musculoskeletal conditions. Med Sci Sports Exerc 30: 1349-1355.

7. Nyanzi CS, Langridge J, Heyworth JR, Mani R (1999) Randomized controlled study of ultrasound therapy in the management of acute lateral ligament sprains of the ankle joint. Clin Rehabil 13: 16-22.

8. Doan N, Reher P, Meghji S, Harris M (1999) In vitro effects of therapeutic ultrasound on cell proliferation, protein synthesis, and cytokine production by human fibroblasts, osteoblasts, and monocytes. J Oral Maxillofac Surg 57: 409-419.

9. Reher P, Elbeshir el-NI, Harvey W, Meghji S, Harris M (1997) The stimulation of bone formation in vitro by therapeutic ultrasound. Ultrasound Med Biol 23: 1251-1258.

10. Reher P, Harris M, Whiteman M, Hai HK, Meghji S (2002) Ultrasound stimulates nitric oxide and prostaglandin E2 production by human osteoblasts. Bone 31: 236-241. 